\title{
Edukasi dan Sosialisasi Gerakan masyarakat Cerdas Menggunakan Obat (Gema Cermat)
}

\author{
Nining dan Yeni* \\ Universitas Muhammadiyah Prof. DR. HAMKA, Jl. Limau II, Kramat Pela, Kebayoran Baru, Jakarta \\ Selatan, DKI Jakarta 12130, Indonesia. \\ *yeni@uhamka.ac.id
}

Submisi: 20 Januari 2018; Penerimaan: 07 April 2019

\begin{abstract}
Tata Kunci:
Abstrak Kopleksitas masalah kesehatan mendorong masyarakat untuk mencari

apoteker;

edukasi; gema

cermat; alternatif pengobatan, baik yang efektif secara terapi dan juga efisien dalam hal sosialisasi; biaya. Swamedikasi menjadi alternatif yang diambil oleh masyarakat. swamedikasi. Penatalaksanaan swamedikasi yang tidak rasional dapat menimbulkan kerugian seperti kesalahan pengobatan karena ketidaktepatan diagnosis sendiri, penggunaan obat yang terkadang tidak sesuai karena informasi bias dari iklan obat di media dan reaksi obat yang tidak diinginkan. Pelaksanaan edukasi dan sosialisasi Gema Cermat bekerjasama dengan PCPM Setu dan apoteker PC IAI kabupaten Bekasi sebagai upaya bersama dalam rangka mewujudkan kepedulian, kesadaran, pemahaman dan keterampilan masyarakat dalam menggunakan obat secara tepat dan benar. Metode yang digunakan adalah CBIA, pemberian brosur Gema Cermat, buku saku cara penggunaan obat dan penggolongan obat, pre-test, post-test dan materi melalui presentasi oral oleh apoteker. Hasil edukasi dan sosialisasi Gema Cermat, yaitu perbaikan tata nilai masyarakan mengenai cara penggunaan obat yang benar dan tepat yang dapat dilihat dari kenaikan nilai rata-rata pre-test 72,5 menjadi 89,7 pada post-test. Masyarakat dapat menganalisis dan mencatat data-data yang perlu diperhatikan pada obat yang akan mereka gunakan sehingga penggunaan obat yang baik dan tepat dapat tercapai.
\end{abstract}

Keywords: education; gema cermat; pharmacist; self medication; socialization.
Abstract Health problems are so complex today. It encourages the people to look for effective treatment alternatives and also efficient in terms of cost. Self medication is being an alternative that has been taken by the the people. Irrational self medication management could lead to disadvantages such as medication errors due to misdiagnosis, inappropriate drugs use due to bias of information from drug advertisements and unwanted drug reactions. Education and Socialization of Gema Cermat was conducted by UHAMKA pharmacist lecturers on December $24^{\text {th }}, 2017$ in cooperation with PCPM Setu and pharmacists PC IAI Bekasi district as an effort in order to improve the concern, awareness, understanding and skill of people in using drugs properly and correctly. The methods used are CBIA, giving the brochure of Gema Cermat, the pocket books of drugs use and drugs classification, pre-test, posttest and materials about Gema Cermat through oral presentation by a pharmacist. The results of education and socialization of Gema Cermat are improving the values of the community regarding the proper and correct use of drugs. It could be seen from the increasing of average pre-test score, 72.5 to 89.7 on post-test. People could analyze and record data that they need to be considered on the drugs use so that the proper and correct use of drugs can be achieved. 


\section{PENDAHULUAN}

Kompleksitas penyakit menular masih merupakan masalah kesehatan, di lain pihak terjadi peningkatan kasus penyakit-penyakit tidak menular atau penyakit degeneratif. Seiring dengan kemajuan teknologi dan perubahan pola hidup masyarakat yang cenderung kurang memperhatikan kesehatan, maka berkembangnya penyakit di masyarakat tidak dapat dielakkan lagi. Berkembangnya penyakit ini mendorong masyarakat untuk mencari alternatif pengobatan yang efektif secara terapi dan juga efisien dalam hal biaya. Berkenaan dengan hal tersebut, swamedikasi menjadi alternatif yang diambil oleh masyarakat (Departemen Kesehatan RI, 2007).

Swamedikasi atau self medication adalah penggunaan obat-obatan tanpa resep oleh seseorang atas inisiatifnya sendiri (FIP, 1999). Dasar hukum swamedikasi adalah peraturan Menteri Kesehatan No. 919/Menkes/Per/X/1993. Swamedikasi biasanya digunakan untuk mengatasi keluhan-keluhan penyakit ringan yang banyak dialami masayarakat, seperti demam, nyeri, pusing, batuk, influenza, sakit maag, diare, penyakit kulit, dan lain-lain. Swamedikasi dilakukan masyarakat untuk meningkatkan keterjangkauan pengobatan. Apabila dalam penggunaannya tidak rasional, swamedikasi dapat menimbulkan kerugian seperti kesalahan pengobatan karena ketidaktepatan diagnosis sendiri, penggunaan obat yang terkadang tidak sesuai karena informasi bias dari iklan obat di media, pemborosan waktu dan biaya apabila timbul reaksi obat yang tidak diinginkan seperti sensitivitas, alergi, efek samping atau resistensi (Holt et al., 1986).

Data riskesdas tahun 2013 menunjukan bahwa 35,2\% rumah tangga menyimpan obat untuk swamedikasi. Merujuk dari 35,2\% rumah tangga yang menyimpan obat, $35,7 \%$ diantaranya menyimpan obat keras, dan $27,8 \%$ di antaranya menyimpan 
antibiotik dan $86,1 \%$ antibiotik tersebut diperoleh tanpa resep. Keadaan ini menunjukan bahwa swamedikasi belum dilaksanakan secara tepat (Riskesdas, 2013).

Pemerintah melalui Kementrian Kesehatan telah mencanangkan Gerakan Masyarakat Cerdas Menggunakan Obat (Gema Cermat). Gema Cermat dicanangkan sebagai upaya bersama antara pemerintah dan masyarakat melalui rangkaian kegiatan dalam rangka mewujudkan kepedulian, kesadaran, pemahaman dan keterampilan masyarakat dalam menggunakan obat secara tepat dan benar (Kepmenkes, 2015). Gema Cermat bertujuan untuk meningkatkan pemahaman dan kesadaran masyarakat tentang pentingnya penggunaan obat secara tepat dan benar. Selain itu, bertujuan untuk meningkatkan kemandirian masyarakat dalam memilih, mendapatkan, menggunakan, menyimpan, dan memusnahkan obat secara tepat dan benar, dan meningkatkan penggunaan obat secara rasional (Kepmenkes, 2015). Gema Cermat perlu kerjasama dan dukungan dari berbagai pihak agar dapat berjalan dengan baik dan berguna bagi masyarakat.

Cara Belajar Insan Aktif atau Community Based Interactive Approach (CBIA) adalah metode edukasi masyarakat yang berorientasi pada peran aktif peserta (face-toface) dalam mencari informasi dan menumbuhkan sikap serta mengubah perilaku (Lathifah dkk., 2015; Rachmawati, 2016). Metode intervensi ini berdasarkan pada proses belajar mandiri, yaitu terdiri dari fasilitator, narasumber dan para peserta (Bela, Suryawati, \& Rustamaji, 2016). Metode CBIA merupakan salah satu kegiatan pemberdayaan masyarakat yang dapat digunakan dalam mengedukasi masyarakat untuk memilih dan menggunakan obat yang benar pada swamedikasi atau penggunaan obat OTC (Over The Counter). Selain itu, yang diharapkan masyarakat, terutama para ibu agar lebih aktif dalam mencari informasi mengenai obat yang digunakan oleh keluarga. 
Oleh karena itu, tujuan swamedikasi dapat tercapai secara optimal (Ariyani \& Rahayu, 2017; Hartayu et al., 2012). Metode Community Based Interactive Approach (CBIA) terbukti efektif dalam meningkatkan pengetahuan, sikap, praktek dan kegiatannya disukai oleh para peserta (Lathifah dkk., 2015; Rachmawati, 2016).

Fakultas Farmasi dan Sains (FFS) Universitas Muhammadiyah Prof. DR. HAMKA (UHAMKA) merupakan salah satu jenis amal usaha Muhammadiyah yang bergerak pada bidang kesehatan. Dosen-dosen FFS UHAMKA umumnya berprofesi sebagai Apoteker. Apoteker adalah sarjana farmasi yang telah lulus sebagai Apoteker dan telah mengucapkan sumpah jabatan Apoteker (Menkes RI, 2017). Agent of Change Gema Cermat adalah apoteker yang memiliki komitmen dan kemampuan mempengaruhi perilaku masyarakat dan tenaga kesehatan dalam rangka pemberdayaan masyarakat untuk meningkatkan penggunaan obat secara rasional. Hal tersebut sesuai dengan visi Ikatan Apoteker Indonesia (IAI), yaitu "Terwujudnya profesi Apoteker yang paripurna, sehingga mampu mewujudkan kualitas hidup sehat bagi setiap manusia" (Ikatan Apoteker Indonesia, 2014). Tenaga Pendidik berkompeten FFS UHAMKA yang berprofesi sebagai Apoteker diharapkan dapat ikut mensukseskan gerakan ini dengan ikut secara aktif memberikan informasi tentang obat kepada masyarakat sebagai bentuk dukungan dan partisipasi aktif dalam pencanangan Gema Cermat. Oleh karena itu, pentingnya pengetahuan mengenai penggunaan obat yang tepat bagi masyarakat mendorong Kami dari Tim Dosen FFS UHAMKA dan Pengurus Cabang Pemuda Muhammadiyah (PCPM) Setu kabupaten Bekasi untuk memberikan edukasi dan sosialisasi Gema Cermat. Pengurus Cabang Ikatan Apoteker Indonesia (PC IAI) Kab. Bekasi selaku organisasi keprofesian juga turut bekerjasama dalam 
mengoptimalkan peran anggota keprofesian dalam penyampaian Gema Cermat di Kabupaten Bekasi.

\section{MASALAH}

Pengurus Cabang (PC) merupakan organ Ikatan Apoteker Indonesia yang melaksanakan tugas-tugas kepengurusan Ikatan di tingkat Kabupaten atau Kota. Salah satu PC yang proaktif melaksanakan kegiatan pengabdian kepada masyarakat dengan melibatkan anggota keprofesian Apoteker adalah PC IAI Kabupaten Bekasi. PC ini diketuai oleh Dra. Rina Mardiana H. Apt. pada Rakercab pertama yang diselenggarakan tahun 2016 disampaikan mengenai alur pembinaan organisasi di tingkat PC yaitu inti utama dari sistem pembinaan yang dibentuk adalah PC ingin membangun pola partisipasi (keterlibatan) dan kontribusi anggota sebesar-besarnya dan meningkatkan peran kolaboratif dengan pihak eksternal lain yang terkait (IAI PC, 2016).

Pengurus Cabang Pemuda Muhammadiyah adalah jenjang struktural Muhammadiyah satu tingkat kecamatan. Pada tingkat yang lebih tinggi dari Pengurus Ranting Pemuda Muhammadiyah, Pengurus cabang Pemuda Muhammadiyah mempunyai manfaat koordinatif untuk seluruh Pengurus Pemuda Muhammadiyah yang ada di lokasi kecamatan itu dan juga mengkoordinasikan gerakan dakwah Islamiyah di seluruh lokasi kecamatan itu melalui beragam wujud, seperti keagamaan, pendidikan, kesejahteraan sosial dan kesehatan. Pentingnya pengetahuan mengenai penggunaan obat yang tepat bagi masyarakat mendorong Pengurus Cabang Pemuda Muhammadiyah kecamatan Setu untuk memberikan edukasi dan sosialisasi Gema Cermat. PC IAI kabupaten Bekasi selaku organisasi keprofesian juga turut bekerjasama dalam mengoptimalkan peran anggota keprofesian dalam penyampaian Gema Cermat di Kabupaten Bekasi. 


\section{METODE PENELITIAN}

Metode yang digunakan dalam penelitian ini adalah Community Based Interactive Approach Method (CBIA) atau Metode Cara Belajar Insan Aktif dengan gambaran IPTEK (Ilmu Pengetahuan dan Teknologi) (Gambar 1). Metode ini dapat dilakukan secara mandiri oleh masyarakat yang didampingi oleh tutor untuk memandu diskusi serta narasumber yang berfungsi menjelaskan hal-hal yang tidak ditemukan jawabannya oleh peserta diskusi.

Evaluasi

1. Peserta memaparkan hasil diskusi

2. Post-Test mengenai Gema Cermat

1. Kelompok masyarakat

2. Kader PCM Kec. Setu

3. Masyarakat Umum

1. Pembagian brosur dan buku kepada masyarakat

2. Pre-Test mengenai Gema Cermat

3. Edukasi dan sosialisasi Gema Cermat oleh Apoteker

4. Simulasi CBIA oleh Apoteker

\section{Sumber: Gambar primer dibuat (2017)}

Gambar 1. Gambaran Ilmu Pengetahuan dan Teknologi

Metode CBIA pertama kali dikembangkan oleh Prof. Dr. Sri Suryawati dari Pusat Studi Farmakologi Klinik dan Kebijakan Obat Universitas Gajah Mada pada tahun 1992 dengan peserta didiknya adalah para ibu. Metode CBIA ini berupa diskusi kelompok kecil yang bersifat interaktif dan proses belajar secara mandiri (self-learning process) dengan memanfaatkan forum yang ada dalam masyarakat seperti arisan, perkumpulan 
dan pengajian. Proses pembelajaran secara aktif dan interaktif membuat metode ini terbukti efektif meningkatkan pengetahuan dan ketrampilan dalam memilih obat. Metode ini juga meningkatkan efisiensi penggunaan obat dalam rumah tangga, sehingga metode CBIA sangat potensial untuk dikembangkan sebagai bentuk pendidikan masyarakat untuk meningkatkan kualitas swamedikasi. Metode CBIA sangat sederhana dan setiap orang dapat melakukannya. Namun, tentu saja untuk menjadi tutor harus melalui proses pelatihan terlebih dahulu dan narasumber haruslah orang yang kompeten dengan permasalahan obat-obatan dan penggunaannya.

Pada penelitian yang telah berjalan, peserta dibagi ke dalam 5 kelompok untuk selanjutnya melakukan diskusi interaktif dan proses belajar secara mandiri (selflearning process). Tutor mendampingi dan bertugas untuk memicu peserta agar belajar mandiri dan aktif serta memiliki sikap kritis dalam mencari informasi. Bila ada yang bertanya, tutor akan berusaha untuk memancing peserta lainnya untuk dapat menganalisa dan mencari jawabannya, kecuali bila pertanyaannya memang membutuhkan jawaban dari ahlinya atau narasumber. Tahapan kegiatan dalam CBIA meliputi (a) pengelompokkan obat menurut kandungan utamanya atau bahan aktifnya; (b) membaca teliti dan membandingkan informasi antar sediaan; dan (c) merangkum temuan kelompok. Sebelum penelitian ini dimulai, dilakukan pendistribusian brosur dan buku saku cara penggunaan obat dan penggolongan obat terlebih dahulu sebagai sarana promosi kesehatan dari pemateri yang dapat dipergunakan sebagai bahan sosialisasi lagi bagi masyarakat umum lainnya. Masyarakat juga diminta untuk mengisi lembar pretest.

Pada kegiatan penyuluhan, narasumber memberikan materi mengenai Gema Cermat. Pada materi tersebut, narasumber menyampaikan pentingnya peran pemerintah 
dan masyarakat dalam meningkatkan penggunaan obat yang tepat dan benar. Obat yang digunakan oleh masyarakat harus memenuhi tepat diagnosis, tepat pemilihan obat, tepat indikasi, tepat pasien, tepat dosis, tepat cara dan lama pemberian, tepat informasi, tepat harga dan waspada efek sampingnya. Masyarakat juga diberikan informasi mengenai waktu penggunan obat, penyimpanan dan cara membuang obat kadaluarsa yang baik dan benar.

Setelah penyampaian materi, dilakukan CBIA dan perwakilan peserta diminta untuk menyampaikan hasil diskusinya. Pada akhir kegiatan penyuluhan, peserta diminta mengisi lembar post-test untuk mengetahui peningkatan pengetahuan dan pemahaman peserta dalam penggunaan obat yang tepat. Hasil penelitian ini diharapkan dapat meningkatkan pemahaman yang baik pada peserta dan untuk dapat mensosialisasikan dengan serius dan berkelanjutan sebagai salah satu cara dalam meningkatkan pemahaman penanganan obat yang tepat di masyarakat ataupun di keluarga masingmasing.

\section{HASIL DAN PEMBAHASAN}

Perbaikan tata nilai masyarakan mengenai cara penggunaan obat yang benar dan tepat dapat dilihat dari perbedaan nilai rata-rata pre-test dan post-test. Nilai rata-rata pre-test adalah 72,5, sedangkan untuk nilai rata-rata post-test adalah 89,7. Pada hasil pre-test 32 peserta, nilai tertinggi, yaitu 90 didapatkan oleh 9 peserta dan nilai terendah, yaitu 40 didapatkan oleh 1 peserta. Pada hasil post-test nilai tertinggi, yaitu 100 didapatkan oleh 12 peserta dan nilai terendah, yaitu 70 didapatkan oleh 1 peserta (Tabel 1 ).

Dari hasil tersebut dapat dilihat bahwa terjadi peningkatan pengetahuan masyarakat tentang penggunaan obat yang tepat. Kepedulian, kesadaran, pemahaman 
dan keterampilan masyarakat meningkat dalam pemilihan, penggunaan, penyimpanan dan pembuangan obat yang baik dan benar.

Tabel 1. Hasil Pre-Test dan Post-Test

\begin{tabular}{|c|c|c|c|c|c|c|c|}
\hline \multicolumn{4}{|c|}{ Pre-Test } & \multicolumn{4}{|c|}{ Post-Test } \\
\hline Peserta & Nilai & Peserta & Nilai & Peserta & Nilai & Peserta & Nilai \\
\hline 1 & 90 & 17 & 40 & 1 & 90 & 17 & 90 \\
\hline 2 & 90 & 18 & 90 & 2 & 100 & 18 & 90 \\
\hline 3 & 80 & 19 & 80 & 3 & 100 & 19 & 90 \\
\hline 4 & 90 & 20 & 80 & 4 & 90 & 20 & 90 \\
\hline 5 & 50 & 21 & 70 & 5 & 80 & 21 & 80 \\
\hline 6 & 60 & 22 & 70 & 6 & 90 & 22 & 80 \\
\hline 7 & 90 & 23 & 50 & 7 & 90 & 23 & 80 \\
\hline 8 & 80 & 24 & 60 & 8 & 100 & 24 & 100 \\
\hline 9 & 60 & 25 & 30 & 9 & 70 & 25 & 80 \\
\hline 10 & 70 & 26 & 90 & 10 & 80 & 26 & 100 \\
\hline 11 & 90 & 27 & 90 & 11 & 100 & 27 & 100 \\
\hline 12 & 90 & 28 & 70 & 12 & 100 & 28 & 80 \\
\hline 13 & 80 & 29 & 70 & 13 & 100 & 29 & 80 \\
\hline 14 & 70 & 30 & 70 & 14 & 100 & 30 & 80 \\
\hline 15 & 60 & 31 & 70 & 15 & 100 & 31 & 80 \\
\hline 16 & 70 & 32 & 70 & 16 & 100 & 32 & 80 \\
\hline \multicolumn{8}{|c|}{ Rata-rata } \\
\hline \multicolumn{4}{|c|}{72,5} & \multicolumn{4}{|c|}{89,7} \\
\hline
\end{tabular}

Sumber: Data primer diolah (2017)

Selain hasil pre-test dan post-test, peserta dapat menganalisi dan mencatat datadata yang perlu diperhatikan pada obat yang akan mereka gunakan sehingga penggunaan obat yang baik dan tepat dapat tercapai (Gambar 2). Data yang dituliskan oleh peserta diskusi antara lain nama bahan aktif, nama dagang, indikasi, aturan pemakaian, efek samping dan kontraindikasi obat. Selain data-data tersebut, peserta juga dapat mengecek tanggal kadaluarsa dari obat pada kemasan primer atau kemasan sekunder obat. 


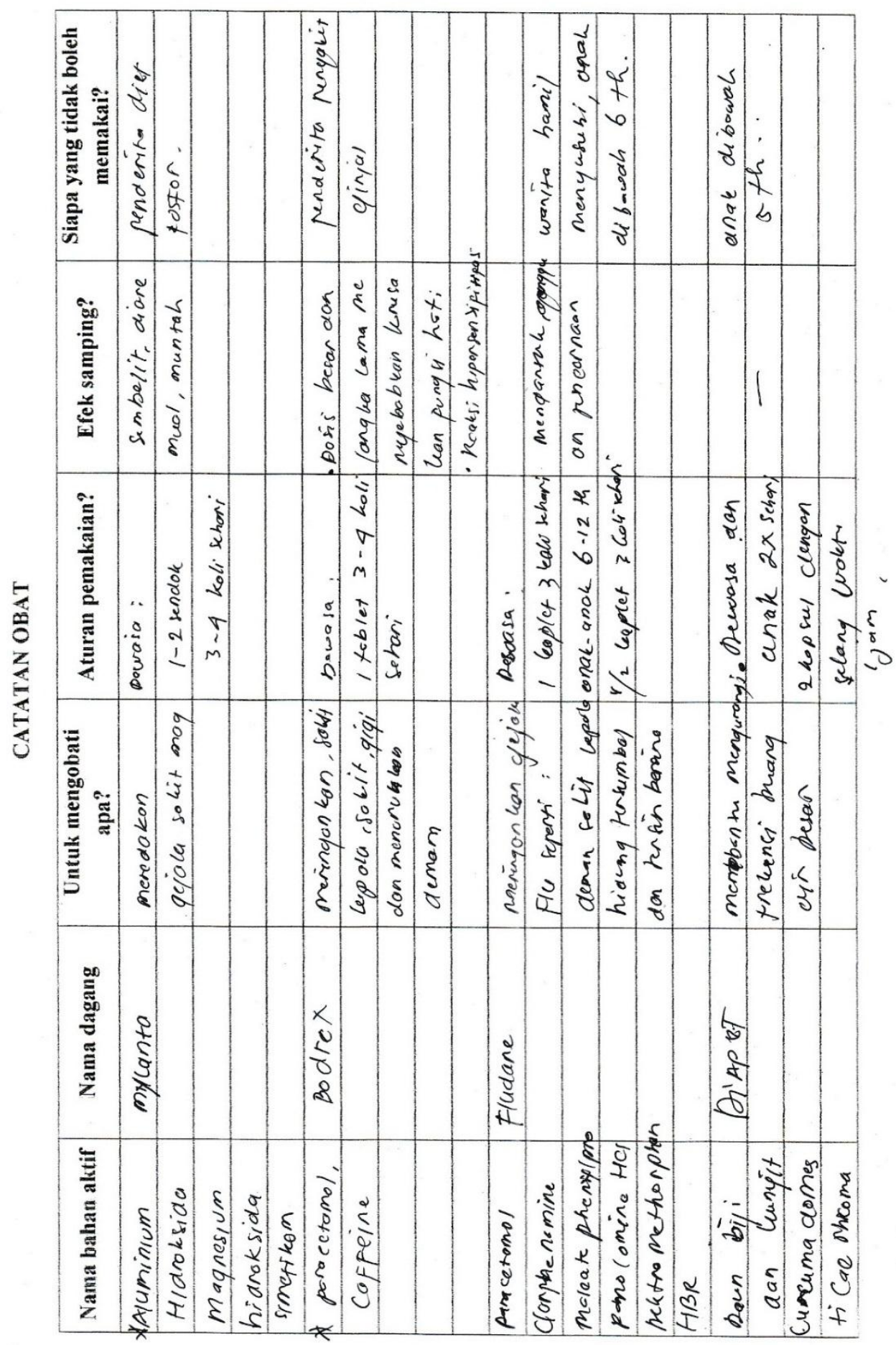

Sumber: Data primer diolah (2017)

Gambar 2. Lembar Kerja Community Based Interactive Approach Method (CBIA)

Tujuan dari edukasi dan sosialisasi Gema Cermat ini untuk meningkatkan pengetahuan obat-obat mana saja yang dapat digunakan bersamaan dan obat-obat mana 
saja yang tidak dapat digunakan bersamaan dengan melihat bahan aktif yang terkandung dalam obat. Selain itu, kegiatan ini juga bertujuan untuk meningkatkan kesadaran akan pentingnya membeli obat di tempat yang terpercaya (apotek) karena pembelian obat di tempat yang tidak berizin memiliki resiko obat tersebut sudah kadaluarsa dan/atau bahkan obat tersebut palsu. Indikator bahwa obat digunakan secara tepat dan benar (rasional), antara lain (a) tepat diagnosis; (b) tepat pemilihan obat; (c) tepat indikasi; (d) tepat pasien; (e) tepat dosis; (f) tepat cara dan lama pemberian; (g) tepat harga; (h) tepat informasi; dan (i) waspada efek samping.

Hasil yang diperoleh menunjukkan peserta memahami bahwa antibiotik harus dibeli dengan resep dokter dan harus dikonsumsi hingga habis agar tidak terjadi resistensi bakteri. Peserta juga mengetahui bahwa obat-obat harus disimpan di tempat yang sesuai dengan perintah yang tertera pada kemasan. Umumnya di tempat yang sejuk, kecuali suppositoria, insulin, dan beberapa obat lainnya, tidak terkena sinar matahari secara langsung, tidak di tempat yang lembab, dan jauh dari jangkauan anakanak. Selain itu, peserta juga mengetahui bahwa pemusnahan obat yang kadaluarsa atau rusak haruslah dipisahkan antara obat dan wadahnya, kemudian etiket yang menempel pada wadahnya pun harus dilepas agat tidak dimanfaatkan oleh orang-orang yang tidak bertanggung jawab.

\section{KESIMPULAN}

Kepedulian, kesadaran, pemahaman dan keterampilan peserta Pengabdian Kepada Masyarakat (PKM) "Edukasi dan Sosialisasi Gema Cermat di Kecamatan Setu Kabupaten Bekasi Bekerjasama dengan PCPM Setu dan PC IAI Kab. Bekasi” mengenai penggunaan obat yang tepat dan benar meningkat. Hal tersebut dapat dilihat 
dari nilai rata-rata pre-test dan post-test, yaitu 72,5 menjadi 89,7. Selain itu, masyarakat juga dapat mengisi lembar kerja CBIA sesuai dengan sampel obat yang diberikan, mulai dari zat aktif yang terkandung, nama dagang, indikasi, aturan pakai, efek samping dan kontraindikasinya.

Pengabdian Kepada Masyarakat (PKM) mengenai edukasi dan sosialisasi Gema Cermat seperti ini perlu dilakukan juga di daerah lain untuk mengurangi resiko kesehatan akibat penggunaaan obat yang tidak tepat dan tidak benar. Oleh karena itu, peran pemerintah, apoteker atau tenaga kesehatan lainnya sangat diharapkan.

\section{DAFTAR PUSTAKA}

Ariyani, H., \& Rahayu, S. (2017). Gerakan Bucer "Ibu Cerdas" Melalui Metode Cara Belajar Insan Aktif (CBIA) Sebagai Sarana Mewujudkan Pemilihan dan Penggunaan Obat Yang Rasional di Kelurahan Sungai Andai Banjarmasin, Kalimantan Selatan. UNES Journal of Community Service, 2(2), 105-112.

Bela, A., Suryawati, S., \& Rustamaji. (2016). Intervensi CBIA untuk Meningkatkan Pengetahuan, Sikap, dan Perilaku Penggunaan Antibiotik yang Rasional pada Anggota Bina Keluarga Balita CBIA. Jurnal Kedokteran Brawijaya, 29(2), 165169.

Departemen Kesehatan RI. (2007). Pedoman Penggunaan Obat Bebas dan Bebas Terbatas. Jakarta: Departemen Kesehatan RI.

FIP. (1999). Joint Statement By The International Pharmaceutical Federation and The World Self-Medication Industry: Responsible Self-Medication. FIP \& WSMI, 1-2. Hartayu, T. S., Mi, M. I., \& Suryawati, S. (2012). Improving of Type 2 Diabetic Patients' Knowledge, Attitude and Practice Towards Diabetes Self-care by 
Implementing Community-Based Interactive Approach-Diabetes Mellitus Strategy. BMC Research Notes, 5(315), 1-6.

Holt, G.A. dan Edwin, L.H. (1986). The Pros and Cons of Self-Medication. Journals of Pharmaceutical Technology. 213-8.

IAI PC Kab. Bekasi. (2016). Artikel: Rakercab Pertama PC IAI Kabupaten Bekasi untuk Menjadikan Profesi Apoteker Lebih Berpartisipasi dan Berkontribusi. Bekasi.

Ikatan Apoteker Indonesia. (2014). Anggaran Dasar dan Anggaran Rumah Tangga Ikatan Apoteker Indonesia (Disahkan pada Kongres Nasional XIX). Jakarta.

Kepmenkes. (2015). Kepmenkes No. 427 tahun 2015 tentang Gerakan Masyarakat Cerdas Menggunakan Obat. Jakarta.

Lathifah, M. A., Ilham, M., \& Wibowo, A. (2015). Perbandingan Metode CBIA dan FGD dalam Peningkatan Pengetahuan dan Ketepatan Caregiver dalam Upaya Swamedikasi Demam pada Anak Abstrak. Pharm Sci Res, 2(2), 89-100.

Menkes RI. (2017). Peraturan Menteri Kesehatan Republik Indonesia Nomor 9 Tahun 2017 tentang Apotek. Jakarta.

Rachmawati, S. (2016). Upaya Peningkatan Pengetahuan Pada Pelajar SMAN 1 Bantul tentang Pencegahan Penyalahgunaan Narkoba dengan Intervensi CBIA-Narkoba. Jurnal IKESMA, 12(1), 1-7.

Riskesdas. (2013). Riset Kesehatan Dasar 2013. Jakarta: Kementrian Kesehatan Republik Indonesia. 
Appendix A

Brosur Gema Cermat

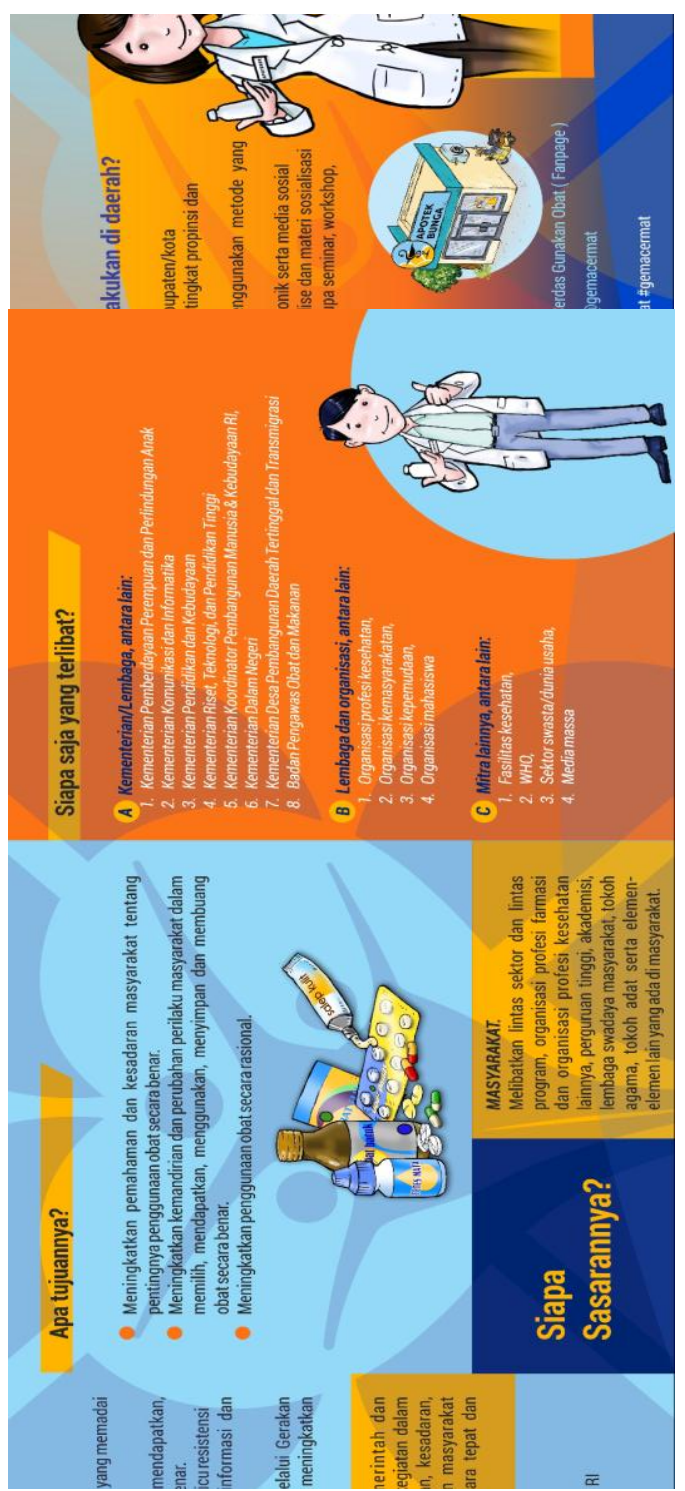


Appendix B

Buku Saku Cara Penggunaan Obat dan Penggolongan Obat
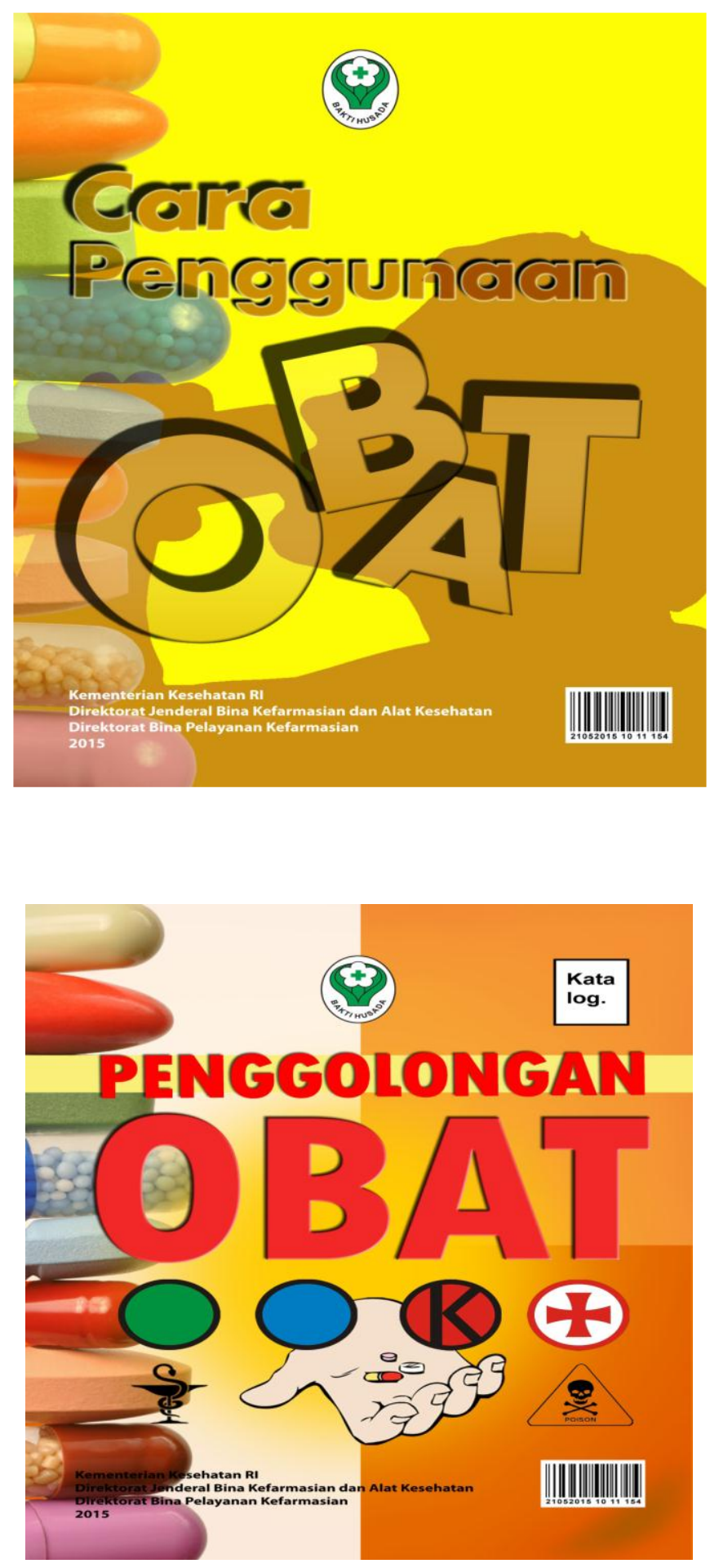


\section{Appendix C}

\section{Soal Pre-Test dan Post-Test}

Soal Pre-Test dan Post-Test

EDUKASI DAN SOSIALISASI GEMARMAT DI KECAMATAN SETU KABUPATEN BEKASI BEKERJASAMA DENGAN IAI PC KAB. BEKASI DAN PCPM CABANG SETU KAB. BEKASI

\section{Desember 2017}

Nama :

Berilah tanda $\mathrm{X}$ pada jawaban yang tepat menurut saudara!

1. Gema Cermat (Gerakan Masyarakat Cerdas Menggunakan Obat) merupakan usaha peningkatan kesehatan yang dilakukan oleh..
a. Pemerintah
b. Masyarakat
c. Pemerintah dan masyarakat
d. Petugas kesehatan

2. Tujuan dilakukannya Gema Cermat adalah...
a. Meningkatkan pemahaman masyarakat tentang penggunaan obat yang benar
b. Meningkatkan tingkat ekonomi masyarakat
c. Meningkatkan jumlah penggunaan obat oleh masyarakat
d. Memberikan pengobatan gratis pada masyarakat

3. Berikut ini merupakan Efek penggunaan obat yang tidak rasional, KECUALI...
a. Efek terapi tidak tercapai
b. Over dosis
c. Kematian
d. Cepat sembuh

4. Dimana sebaiknya kita membeli obat?
a. Warung
b. Apotek
c. Rumah sakit
d. Toko jamu

5. Penggunaan antibiotik seharusnya...

a. Dihabiskan sesuai dengan resep

b. Dihentikan jika sudah sembuh

c. Diminum dalam jumlah banyak agar cepat sembuh

d. Dihentikan jika tidak kunjung sembuh

6. Berikut merupakan informasi tentang obat yang harus diketahui pasien, KECUALI...
a. Komposisi
b. Indikasi
c. Dosis
d. Produsen

7. Obat yang bisa dibeli tanpa resep dokter adalah...
a. Obat bebas
b. Obat keras
c. Obat narkotika
d. Obat psikotropika

8. Jika aturan pakai obat $3 \mathrm{x}$ sehari maka obat tersebut diminum setiap...
a. 24 jam sekali
b. 12 jam sekali
c. 8 jam sekali
d. 6 jam sekali

9. Jika obat harus diminum setelah makan artinya...
a. Obat diminum 2 jam setelah makan
b. Obat diminum 4 jam setelah makan
c. Obat diminum 5 jam setelah makan
d. Obat diminum 5 menit setelah makan

10. Obat di rumah yang sudah rusak sebaiknya...
a. Langsung dibuang ke tempat sampah
b. Dibiarkan saja
c. Dilepas labelnya dan dihancurkan
d. Tidak ada jawaban yang benar

Jawaban yang benar 